\title{
CORRELAÇÃO ENTRE TESTES DE VIGOR EM SEMENTES DE MAXIXE ${ }^{1}$
}

\author{
SALVADOR BARROS TORRES ${ }^{2}$, MAGNÓLIA APARECIDA SILVA DA SILVA 3 , IONE MARIA SOARES DE CARVALHO 4 \\ e MANOEL ABÍLIO DE QUEIRÓZ ${ }^{5}$
}

\begin{abstract}
RESUMO - O objetivo deste trabalho foi comparar a eficiência de diferentes testes para determinação da qualidade fisiológica de sementes de maxixe (Cucumis anguria L.), visando melhorar sua utilização como testes de qualidade e verificar suas relações com a emergência de plântulas em campo. Foram avaliadas sementes de sete lotes, pelos testes de germinação, primeira contagem de germinação, condutividade elétrica a 4 e 24 horas, envelhecimento acelerado, deterioração controlada, teste de frio sem solo e emergência de plântulas em campo. O trabalho foi desenvolvido no Laboratório de Análise de Sementes e em um campo experimental da Embrapa-CPATSA, em Petrolina, PE, no período de janeiro a maio de 1996. Nos testes de laboratório, o delineamento experimental foi inteiramente casualizado, e nos testes de campo foi usado o delineamento em blocos casualizados - ambos com quatro repetições de cinqüenta sementes, sendo as médias comparadas pelo teste de Tukey a $1 \%$ de probabilidade. Os testes de germinação e vigor foram eficientes para detectar diferenças de qualidade fisiológica entre lotes de sementes de maxixe. Os testes de deterioração controlada e de frio sem solo foram mais consistentes na separação dos lotes em diferentes níveis de vigor, e ao mesmo tempo apresentaram os maiores níveis de correlação com a emergência de plântulas em campo.
\end{abstract}

Termos para indexação: Cucumis anguria, qualidade fisiológica de sementes.

\section{CORRELATION AMONG VIGOR TESTS ON GHERKIN SEEDS}

\begin{abstract}
This work was carried out with the objective of comparing the efficiency of different tests in the physiological quality of gherkin seeds (Cucumis anguria L.), looking for information for a better utilization of these quality control tests, as well as verifying their relation at field emergency. Seven lots of gherkin seeds were evaluated by the germination test, first count, electrical conductivity at 4 and 24 hours, accelerated aging, controlled damage, cold without soil, and field emergency. The trials were carried out at the Seed Lab and at an experimental field of Embrapa-CPATSA, at Petrolina, PE, Brazil, from January to May 1996. In the lab tests, a completely randomized design was used, and in the field tests, a randomized block design was used - both of them with four repetitions of fifty seeds, being the means compared by the Tukey test, at $1 \%$ of probability. The germination and vigor tests were effective to detect differences of physiological quality among gherkin seed lots. The damage control and cold without soil tests were more stable on the division of the lots by the vigor levels and, at the same time, showed the highest correlation with field emergency.
\end{abstract}

Index terms: Cucumis anguria, physiological quality of seeds.

\section{INTRODUÇÃO}

${ }^{1}$ Aceito para publicação em 20 de julho de 1998 .

${ }^{2}$ Eng. Agr., M.Sc., EMPARN/Embrapa-Centro de Pesquisa Agropecuária do Trópico Semi-Árido (CPATSA), Caixa Postal 23, CEP 56300-000 Petrolina, PE. E-mail: sbtorres@carpa.ciagri.usp.br

${ }^{3}$ Eng $\underline{a}$ Agra, M.Sc., Embrapa-CPATSA. Bolsista do CNPq.

${ }^{4}$ Eng ${ }^{\underline{a}}$ Agr ${ }^{\mathrm{a}}$, Embrapa-CPATSA. Bolsista do CNPq.

${ }^{5}$ Eng. Agr., Ph.D., Embrapa-CPATSA.
A produção de sementes de maxixe, no Brasil, é baixa, em comparação com a de outras hortaliças. Em um levantamento de produção e importação de sementes de hortaliças, realizado por Nascimento et al. (1994), foi constatado que a produção de sementes de maxixe, em 1989, era de $1.901 \mathrm{~kg}$, sendo os estados do Rio Grande do Sul e Pernambuco os únicos produtores, com 1.242 e $659 \mathrm{~kg}$, respectivamente. 
Partindo-se do princípio de que o uso de sementes de alta qualidade é fundamental para a instalação e produção de uma cultura, e sendo a utilização do teste-padrão de germinação como único indicativo da qualidade fisiológica e ante o fato de o mesmo ser muito questionado, pesquisadores têm procurado desenvolver técnicas para a aplicação de testes de vigor na avaliação da qualidade das sementes (Vieira et al., 1993). Entretanto, diversos testes de vigor têm sido idealizados, procurando avaliar e correlacionar, com precisão, o comportamento de lotes de sementes em laboratório e no campo, como por exemplo, o teste de frio para milho (Cícero \& Vieira, 1994), teste de envelhecimento acelerado para soja (Vieira et al., 1994) e o teste de condutividade elétrica para ervilha (Caliari \& Marcos Filho, 1990). Porém, são raros os estudos, em todos os aspectos, acerca da cultura do maxixe, principalmente, no tocante à tecnologia de sementes. Pesquisas sobre as metodologias adequadas para avaliar o vigor das sementes, e estudos para comparar métodos de avaliação da qualidade fisiológica de sementes de maxixe são escassos.

O objetivo deste trabalho foi comparar a eficiência de diferentes testes de vigor para determinação da qualidade fisiológica de sementes de maxixe, visando melhorar sua utilização como testes de qualidade e verificar suas relações com a emergência de plântulas no campo.

\section{MATERIAL E MÉTODOS}

O trabalho foi desenvolvido no Laboratório de Análise de Sementes e em um campo experimental da EmbrapaCentro de Pesquisa Agropecuária do Trópico Semi-Árido (CPATSA), em Petrolina, PE, no período de janeiro a maio de 1996. Foram utilizados sete lotes de sementes de maxixe, beneficiadas e não tratadas, fornecidos pela empresa Isla S/A, do Estado do Rio Grande do Sul. No momento da recepcão, foi determinado o teor de umidade das sementes em estufa, a $105 \pm 3^{\circ} \mathrm{C}$, por 24 horas, utilizando-se duas subamostras de cada lote, conforme as indicações das Regras para Análise de Sementes (Brasil, 1992). Durante a fase experimental, as sementes permaneceram armazenadas em sacos de papel sob condições controladas $\left(10^{\circ} \mathrm{C}\right.$ e $35 \%$ de umidade relativa).

Para avaliar a qualidade fisiológica, as sementes foram submetidas aos seguintes testes:
Teste de germinação - conduzido em temperatura alternada de $20-30^{\circ} \mathrm{C}$, semeadura efetuada em papel mataborrão, com quatro repetições de 50 sementes, seguindo os procedimentos previstos em Brasil (1992);

Primeira contagem de germinação - efetuado conjuntamente com o teste de germinação, determinando-se a porcentagem de plântulas normais no quarto dia após a sua instalação, conforme prescrições das Regras para Análise de Sementes (Brasil, 1992);

Condutividade elétrica - foram selecionadas e pesadas quatro repetições de 25 sementes de cada lote, as quais foram imersas em $75 \mathrm{~mL}$ de água destilada a $20^{\circ} \mathrm{C}$. As leituras da condutividade elétrica da solução foram medidas em condutivímetro, marca Digimed, após 4 e 24 horas de incubação. Os resultados foram expressos em $\mu \mathrm{S} / \mathrm{cm} / \mathrm{g}$ de sementes (Vieira, 1994);

Envelhecimento acelerado - utilizaram-se 200 sementes por lote, em quatro repetições de 50 sementes, distribuídas sobre bandejas de tela de alumínio, fixadas no interior de caixas de plástico, tipo Gerbox, a $41^{\circ} \mathrm{C}$ e $100 \%$ de umidade relativa, por um período de 48 horas. Decorrido este período, as sementes foram colocadas para germinar, seguindo-se as recomendações para o teste de germinação (Brasil, 1992). A avaliação das plântulas foi realizada quatro dias após a semeadura, calculando-se a porcentagem de plântulas normais;

Deterioração controlada - cinco gramas de sementes de cada um dos lotes, com teores de umidade conhecidos (Tabela 1), foram colocadas dentro de uma placa-de-petri, a qual continha em seu interior uma folha de papel de filtro previamente umedecida, e pesadas com freqüência, utilizando-se a fórmula do desconto de peso $\{\mathrm{Pi} \times(100-\mathrm{Ui})=$ Pf x $(100-U f)\}$, até o momento em que as sementes atingiram $19 \%$ de umidade. Em seguida, as sementes foram acondicionadas em cápsulas de alumínio hermeticamente fechadas, à temperatura de $10^{\circ} \mathrm{C}$, e aí conservada durante doze horas, para que fosse assegurada uma distribuição uniforme da umidade. Decorrido este período, as amostras foram colocadas em sacos aluminizados, os quais foram vedados com fita gomada e incubados em banho-maria a $45^{\circ} \mathrm{C}$, por 24 horas (Matthews, 1980 citado por Lima, 1993); em seguida, foram retirados do banho e submetidos ao teste de germinação (Brasil, 1992). Os resultados foram expressos em porcentagem de plântulas normais;

Teste de frio sem solo - quatro repetições de 50 sementes por lote foram distribuídas em rolos de papel umedecido em quantidade de água equivalente a 2,0 vezes o peso do papel. Após a semeadura, os rolos foram colocados no interior de sacos de plástico e vedados com fita adesiva, sendo mantidos em câmara regulada a $10^{\circ} \mathrm{C}$, durante sete dias (Cícero \& Vieira, 1994). Após este período, foram 
retirados dos sacos de plástico e transferidos para um germinador à temperatura alternada de $20-30^{\circ} \mathrm{C}$, onde permaneceram por quatro dias, contando-se, a seguir, o número de plântulas normais (Brasil, 1992);

Emergência de plântulas em campo - o teste foi realizado com quatro repetições de 50 sementes por lote. As sementes de cada repetição foram semeadas a $1 \mathrm{~cm}$ de profundidade, em sulcos com $1 \mathrm{~m}$ de comprimento e com distância de $30 \mathrm{~cm}$ entre si. As contagens, efetuadas 21 dias após a semeadura, determinaram a porcentagem de emergência de plântulas (Nakagawa, 1994).

Nos testes de laboratório, o delineamento experimental foi inteiramente casualizado e, nos testes de campo foi usado o delineamento em blocos casualizados, ambos com quatro repetições. As médias foram comparadas pelo teste de Tukey, a $1 \%$ de probabilidade, e os valores, expressos em porcentagem, foram transformados em arc sen da raiz quadrada de $\mathrm{x} / 100$.

\section{RESULTADOS E DISCUSSÃO}

O grau de umidade das sementes, embora não tenha sido analisado estatisticamente, foi, de um modo geral, semelhante nos sete lotes estudados $(6,9,7,0,7,0,7,0,7,2,7,3$ e 7,3, respectivamente). Este fato é importante na execução dos testes, uma vez que a uniformização da umidade das sementes é imprescindível para a padronização das avaliações e obtenção de resultados consistentes (Marcos Filho et al., 1987; Loeffler et al., 1988).

Analisando-se os resultados apresentados na Tabela 1, observa-se que, em termos de germinação, o lote 6 destacou-se dos demais, apesar de ser estatisticamente semelhante aos lotes 2 e 3, que não diferiram dos lotes 1, 4 e 5; em contrapartida, o lote 7 apresentou menor porcentagem de germinação. Verifica-se, na Tabela 2, que houve correlação significativa entre este teste e os testes de condutividade elétrica por 24 horas de embebição $(r=-0,492)$, envelhecimento acelerado $(\mathrm{r}=0,725)$, deterioração controlada $(r=0,730)$, frio sem solo $(r=0,720)$ e emergência de plântulas em campo $(\mathrm{r}=0,583)$. Resultados semelhantes foram encontrados por Lima (1993) e Andrade et al. (1995), quando avaliaram sementes de cebola e cenoura, respectivamente.

O teste de primeira contagem de germinação (Tabela 1) identificou o lote 3 como de qualidade fisiológica superior, embora não diferindo estatisticamente do lote 6 , que mostrou-se semelhante aos lotes 2 e 5 . Estes, por sua vez, foram significativamente semelhantes aos lotes 1 e 4, o que está de acordo com os resultados de germinação. O lote 7 apresentou o pior desempenho de qualidade, revelando a mesma tendência observada no teste anterior, na separação dos lotes de sementes de maxixe em di-

TABELA 1. Resultados dos testes de germinação, primeira contagem de germinação, condutividade elétrica em 4 e 24 horas de lixiviação, envelhecimento acelerado, deterioração controlada, teste de frio sem solo e emergência de plântulas em campo de sete lotes de sementes de maxixe ${ }^{1}$.

\begin{tabular}{|c|c|c|c|c|c|c|c|c|}
\hline Lote & $\begin{array}{c}\text { Teste de } \\
\text { germinação } \\
(\%)\end{array}$ & $\begin{array}{l}\text { Primeira con- } \\
\text { tagem de ger- } \\
\text { minação }(\%)\end{array}$ & $\begin{array}{l}\text { Condutividade } \\
\text { elétrica/4 h } \\
(\mu \mathrm{S} / \mathrm{cm} / \mathrm{g})\end{array}$ & $\begin{array}{c}\text { Condutividade } \\
\text { elétrica/24 h } \\
(\mu \mathrm{S} / \mathrm{cm} / \mathrm{g})\end{array}$ & $\begin{array}{l}\text { Envelheci- } \\
\text { mento ace- } \\
\text { lerado }(\%)\end{array}$ & $\begin{array}{c}\text { Deterioração } \\
\text { controlada } \\
(\%)\end{array}$ & $\begin{array}{l}\text { Teste de frio } \\
\text { sem solo }(\%)\end{array}$ & $\begin{array}{c}\text { Emergência de } \\
\text { plântulas em campo } \\
(\%)\end{array}$ \\
\hline 1 & $57 \mathrm{c}$ & $48 \mathrm{c}$ & $25,021 \mathrm{~d}$ & $39,752 \mathrm{c}$ & $50 \mathrm{bc}$ & $60 \mathrm{~b}$ & $44 c$ & $24 \mathrm{de}$ \\
\hline 2 & $67 a b c$ & $59 \mathrm{bc}$ & $16,174 \mathrm{e}$ & $28,077 \mathrm{~d}$ & $74 a$ & $70 \mathrm{ab}$ & $63 b$ & $43 b c$ \\
\hline 3 & $81 \mathrm{ab}$ & $74 a$ & $34,819 \mathrm{bc}$ & $44,304 \mathrm{bc}$ & $73 a$ & $76 a$ & $79 a$ & $59 a$ \\
\hline 4 & $60 c$ & $51 \mathrm{c}$ & $31,318 \mathrm{~cd}$ & $50,654 \mathrm{ab}$ & $41 \mathrm{~cd}$ & $36 \mathrm{c}$ & $38 \mathrm{c}$ & $20 \mathrm{de}$ \\
\hline 5 & $66 \mathrm{bc}$ & $59 \mathrm{bc}$ & $39,922 \mathrm{ab}$ & $46,816 \mathrm{bc}$ & $66 \mathrm{ab}$ & $65 \mathrm{ab}$ & $68 \mathrm{ab}$ & $55 \mathrm{ab}$ \\
\hline 6 & $82 a$ & $72 \mathrm{ab}$ & $34,878 \mathrm{bc}$ & $42,958 \mathrm{bc}$ & $60 \mathrm{abc}$ & $72 \mathrm{ab}$ & $59 \mathrm{~b}$ & $34 \mathrm{~cd}$ \\
\hline 7 & $20 \mathrm{~d}$ & $11 \mathrm{~d}$ & $44,714 \mathrm{a}$ & $58,297 \mathrm{a}$ & $23 \mathrm{~d}$ & $13 d$ & $15 \mathrm{~d}$ & $18 \mathrm{e}$ \\
\hline Média & 61 & 53 & 32,406 & 44,408 & 55 & 56 & 52 & 36 \\
\hline $\mathrm{F}$ & $25,6^{* *}$ & $38,6^{* *}$ & $21,0^{* *}$ & $11,8^{* *}$ & $14,6^{* *}$ & $41,4^{* *}$ & $34,8^{* *}$ & $16,3^{* *}$ \\
\hline CV (\%) & 11,1 & 10,4 & 10,4 & 10,1 & 14,5 & 10,4 & 11,4 & 18,6 \\
\hline DMS & 16,1 & 13,0 & 7,9 & 10,5 & 18,7 & 13,6 & 14,0 & 15,8 \\
\hline
\end{tabular}

1 Médias seguidas da mesma letra, na coluna, não diferem estatisticamente entre si.

** Significativo a $1 \%$ de probabilidade, pelo teste de Tukey. 
ferentes níveis de vigor. O teste de primeira contagem de germinação correlacionou-se significativamente com os testes de germinação $(r=0,779)$, condutividade elétrica por 24 horas de embebição $(r=-0,515)$, envelhecimento acelerado $(0,793)$, deterioração controlada $(r=0,769)$, frio sem solo $(\mathrm{r}=0,771)$ e emergência de plântulas em campo $(0,640)$ (Tabela 2).

Os valores de condutividade elétrica dos solutos lixiviados nos lotes de sementes de maxixe apresentados na Tabela 1 são provenientes de duas leituras realizadas após 4 e 24 horas de embebição. Os resultados indicaram o lote 7 , nos dois períodos de embebição, como o que mais lixiviou solutos, constituindo-se como de baixa qualidade fisiológica; por outro lado, o lote 1 apresentou a menor lixiviação de solutos. Desta forma, os resultados revelam este lote como de alta qualidade fisiológica. A velocidade de lixiviação de solutos foi mais rápida após quatro horas de embebição, apresentando uma média geral de $32,406 \mu \mathrm{S} / \mathrm{cm} / \mathrm{g}$ de semente comparado com $44,408 \mu \mathrm{S} / \mathrm{cm} / \mathrm{g}$ de semente após 24 horas. Resultados semelhantes foram relatados por Simon \& Mills (1983), citados por Andrade et al. (1995) em sementes de ervilha, quanto à velocidade do processo de lixiviação. Na Tabela 2, observa-se que os dois períodos de embebição correlacionaram-se entre si $(\mathrm{r}=0,863)$ e que não houve correlação significativa com a emergência de plântulas em campo. De modo geral, os resultados dos testes de condutividade elétrica apresentaram correlação negativa, porém significativa com os testes de germinação $(r=-0,492)$, envelhecimento acelerado $(r=-0,417)$ e $(r=-0,662)$, deterioração controlada $(\mathrm{r}=-0,444) \mathrm{e}(\mathrm{r}=-0,688)$, e frio sem solo $(r=-0,554)$. Isto é, aos maiores valores de lixiviação de solutos corresponderam às menores porcentagens de plântulas normais como resultados destes testes, o que mostra ser este um bom parâmetro de avaliação da qualidade de sementes. Resultados semelhantes foram encontrados por Andrade et al. (1995) quando avaliaram sete lotes de sementes de cenoura.

Os dados relativos ao teste de envelhecimento acelerado (Tabela 1) apontaram os lotes 2 e 3 como os mais vigorosos, apesar de estatisticamente semelhantes aos lotes 5 e 6 . Estes, por sua vez, foram significativamente semelhantes aos lotes 1 e 4 . O lote 7 obteve baixo desempenho de qualidade, não diferindo do lote 4. Observa-se que, de certo modo, o comportamento dos lotes foi semelhante aos resultados encontrados nos testes anteriores. Embora os testes tenham-se correlacionado significativamente entre si (Tabela 2), os testes de deterioração controlada e frio obtiveram, em valores absolutos, as maiores correlações ( $r=0,879$ e $r=0,878$, respectivamente). Resultados semelhantes também foram encontrados por Andrade et al. (1995) e Lima (1993).

Os dados referentes ao teste de deterioração controlada (Tabela 1) demonstraram que o comportamento dos lotes foi semelhante ao dos testes anteriores. Pelos resultados, destaca-se o lote 3 como mais vigoroso, embora não tenha diferido estatisticamente dos lotes 2,5 e 6 . Estes, por sua vez, foram semelhantes ao lote 1 . Os lotes $4 \mathrm{e} 7$ apresentaram resultados

TABELA 2. Coeficientes de correlacão simples (r) entre as variáveis analisadas nos testes de avaliação da qualidade fisiológica de sementes de maxixe ${ }^{1}$.

\begin{tabular}{|c|c|c|c|c|c|c|c|}
\hline Testes & G. & C.E. 4 & C.E. 24 & E.A. & D.C. & T.F. & E.C. \\
\hline P.C.G. & $0,779^{* *}$ & $-0,315^{\mathrm{ns}}$ & $-0,515^{* *}$ & $0,793^{* *}$ & $0,769^{* *}$ & $0,771^{* *}$ & $0,640^{* *}$ \\
\hline G. & & $-0,312^{\mathrm{ns}}$ & $-0,492^{* *}$ & $0,725^{* *}$ & $0,730^{* *}$ & $0,720^{* *}$ & $0,583^{* *}$ \\
\hline C.E. 4 & & & $0,863^{* *}$ & $-0,417^{*}$ & $-0,444^{*}$ & $-0,268^{\mathrm{ns}}$ & $-0,028^{\text {ns }}$ \\
\hline C.E. 24 & & & & $-0,662^{* *}$ & $-0,688^{* *}$ & $-0,554^{*}$ & $-0,323^{\text {ns }}$ \\
\hline E.A. & & & & & $0,879^{* *}$ & $0,878^{* *}$ & $0,734^{* *}$ \\
\hline D.C. & & & & & & $0,872^{* *}$ & $0,987^{* *}$ \\
\hline T.F. & & & & & & & $0,957^{* *}$ \\
\hline
\end{tabular}

${ }^{1} \mathrm{G}=$ germinação; P.C.G. = primeira contagem de germinação; C.E. 4 e C.E. 24 = condutividade elétrica em 4 e 24 horas, respectivamente; E.A. = envelhecimento acelerado; D.C. = deterioração controlada; T.F. = teste de frio sem solo; E.C. = emergência de plântulas em campo; ns $=$ não-significatico $; *$ significativo a $5 \%$ de probabilidade; $* *=$ significativo a $1 \%$ de probabilidade. 
bastante inferiores, tendo o lote 7 como o de pior qualidade. Este teste apresentou resultados mais consistentes em relação aos testes anteriores, quanto à separação dos lotes em diferentes níveis de vigor. Situação semelhante foi verificada por Rosseto \& Marcos Filho (1995), quando avaliaram a qualidade fisiológica de três lotes de sementes de soja, cultivar IAC-15, através dos testes de envelhecimento acelerado e deterioração controlada. O teste de deterioração controlada também correlacionou-se significativamente com todos os demais testes (Tabela 2), destacando-se, em ordem decrescente de valor absoluto, as maiores correlações nos testes de emergência de plântulas em campo $(r=0,987)$, envelhecimento acelerado $(r=0,879)$, frio sem solo $(r=0,872)$, primeira contagem de germinação $(r=0,769)$ e germinação $(r=0,730)$. Resultados concordantes foram encontrados por Lima (1993) em sementes de cebola.

O teste de frio sem solo (Tabela 1) apresentou também melhor separação dos lotes em diferentes níveis de vigor. Observa-se que o lote 3 apresentou melhor porcentagem de plântulas normais, porém, não diferiu do lote 5 . Este, por sua vez, também não diferiu dos lotes 2 e 6 . Os lotes 1 e 4 não diferiram estatisticamente entre si, enquanto o lote 7 obteve o pior resultado. Segundo Grabe (1976), os lotes de qualidade adequada devem apresentar, no mínimo, 70 a $80 \%$ de plântulas normais como resultado do teste de frio, valor observado somente no lote 3 . Os maiores valores de correlação foram observados entre os testes de emergência de plântulas em campo $(r=0,957)$, envelhecimento acelerado $(r=0,878)$, deterioração controlada $(\mathrm{r}=0,872)$ e primeira contagem de germinação $(r=0,771)$. Resultados similares foram encontrados por Piana et al. (1995), que informam ser este teste o que melhor se correlacionou com a emergência de plântulas em campo e com a obtenção de mudas vigorosas de cebola, além de identificar os lotes com diferentes níveis de vigor.

Os resultados referentes ao teste de emergência de plântulas em campo (Tabela 1) demostraram que o comportamento dos lotes foi semelhante aos resultados dos testes anteriores. Embora todos os lotes tenham apresentado resultados baixos de porcentagem de emergência de plântulas em campo (média de $36 \%$ ), o lote 3 obteve melhor desempenho, embora não diferindo estatisticamente do lote 5 , que mos- trou-se semelhante ao lote 2 , e este similar ao lote 6 . Os lotes 1, 4 e 7 apresentaram os mais baixos resultados de porcentagem de plântulas em campo, tendo o lote 7 obtido o pior resultado. Observando-se, na Tabela 2, as correlações obtidas entre os testes de laboratório e a emergência de plântulas em campo, destaca-se o teste de frio sem solo, em valor absoluto, com a maior correlação $(r=0,957)$.

Numa análise geral, verifica-se dentre os sete lotes de sementes de maxixe, que um ou dois lotes sempre apresentaram níveis de vigor superiores aos demais, e, da mesma forma, um ou mais lotes demonstraram desempenho inferior de qualidade; no entanto, embora a identificação dos melhores lotes sempre tenha sido evidente, a classificação dos lotes menos vigorosos variou, de certa forma, em função do teste utilizado. De fato, a identificação dos lotes com qualidade intermediária pode sofrer variações, dependendo do teste utilizado, devendo-se considerar que os testes de laboratório devem ser suficientes para, pelo menos, diferenciar lotes de potencial elevado, daqueles que apresentam potencial deficiente para o estabelecimento de plântulas em campo (Marcos Filho et al., 1985).

Neste aspecto, os resultados desta pesquisa demonstraram a existência de alguns testes de execução bastante simples, capazes de fornecer informações de grande utilidade em programas de controle de qualidade de sementes de maxixe.

\section{CONCLUSÕES}

1. Os testes de germinação e vigor são eficientes para detectar diferenças de qualidade fisiológica entre lotes de sementes de maxixe.

2. Os testes de deterioração controlada e de frio sem solo são mais consistentes na separação dos lotes em diferentes níveis de vigor, e apresentam os maiores níveis de correlação com a emergência de plântulas em campo.

\section{AGRADECIMENTOS}

À gerente administrativa/financeira da empresa Isla S/A, Porto Alegre, RS, Tânia Ma ${ }^{\mathrm{a}}$. Lohr Pires, pelas doações das sementes de maxixe e embalagens aluminizadas. 


\section{REFERÊNCIAS}

ANDRADE, R.N. de; SANTOS, D.S.B. dos; SANTOS FILHO, B.G. dos; MELLO, V.D.C. Correlação entre testes de vigor em sementes de cenoura armazenadas por diferentes períodos. Pesquisa Agropecuária Gaúcha, Porto Alegre, v.1, n.2, p.153-162, 1995.

BRASIL. Ministério da Agricultura e da Reforma Agrária. Regras para análise de sementes. Brasília: SNDA/ DNDV/CLAV, 1992.365p

CALIARI, M.F.; MARCOS FILHO, J. Comparação entre métodos para avaliação da qualidade fisiológica de sementes de ervilha (Pisum sativum L.). Revista Brasileira de Sementes, Brasília, v.12, n.3, p.5275, 1990 .

CÍCERO, S.M.; VIEIRA, R.D. Teste de frio. In: VIEIRA, R.D.; CARVALHO, N.M. de. Testes de vigor em sementes. Jaboticabal: FUNEP, 1994. p.151-164.

GRABE, D.F. Measurement of seed vigor. Journal of Seed Technology, Springfield, v.1, n.2, p.18-31, 1976.

LIMA, D. de. Avaliação da viabilidade e vigor de sementes de cebola (Allium cepa L.). Pelotas: UFPel, 1993. 61p. Dissertação de Mestrado.

LOEFFLER, T.M.; TEKRONY, D.M.; EGLI, D.B. The bulk conductivity test as an indicator of soybean seed quality. Journal of Seed Technology, Springfield, v.12, n.1, p.37-53, 1988.

MARCOS FILHO, J.; CARVALHO, R.V.; CÍCERO, S.M.; DEMÉTRIO, C.G.B. Qualidade fisiológica e comportamento de sementes de soja (Glycine max (L.) Merrill) no armazenamento e no campo. Anais da Escola Superior de Agricultura "Luiz de Queiroz", Piracicaba, v.42, n.1, p.195-249, 1985.
MARCOS FILHO, J.; CÍCERO, S.M.; SILVA, W.R. da. Avaliação da qualidade das sementes. Piracicaba: FEALQ, 1987. 230p.

NAKAGAWA, J. Testes de vigor baseados na avaliação das plântulas. In: VIEIRA, R.D.; CARVALHO, N. $M$. de. Testes de vigor em sementes. Jaboticabal: FUNEP, 1994. p.49-85.

NASCIMENTO, W.M.; MOREIRA, H.M.; MENEZES, J.E.; GUEDES, A.C. Produção e importação de sementes de hortaliças no Brasil-1986/1989. Brasília: Embrapa-CNPH, 1994. 175p.

PIANA, Z.; TILLMANN, M.A.A.; MINAMI, K. Avaliação da qualidade fisiológica de sementes de cebola e sua relação com a produção de mudas vigorosas. Revista Brasileira de Sementes, Brasília, v.17, n.2, p.149-153, 1995.

ROSSETTO, C.A.V.; MARCOS FILHO, J. Comparação entre os métodos de envelhecimento acelerado e de deterioração controlada para avaliação da qualidade fisiológica de sementes de soja. Scientia Agricola, Piracicaba, v.52, n.1, p.123-131, 1995.

VIEIRA, E.R.; VIEIRA, M. das G.G.C.; FRAGA, A.C.; SILVEIRA, J.F. da. Comparação entre métodos para avaliação da qualidade fisiológica de sementes de feijão (Phaseolus vulgaris L.). Ciência e Prática, Lavras, v.17, n.1, p.10-15, 1993.

VIEIRA, R.D. Teste de condutividade elétrica. In: VIEIRA, R.D.; CARVALHO, N.M. de. Testes de vigor em sementes. Jaboticabal: FUNEP, 1994. p.103-132.

VIEIRA, R.D.; CARVALHO, N.M. de; SADER, R. Testes de vigor e suas possibilidades de uso. In: VIEIRA, R.D.; CARVALHO, N.M. de. Testes de vigor em sementes. Jaboticabal: FUNEP, 1994. p.31-47. 